\title{
Editorial: Corporate Social Responsibility in Latin America

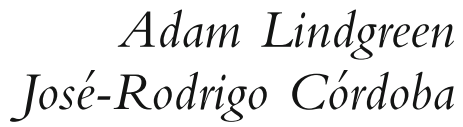

\section{Introduction}

During the last decade and with the advent of globalisation, the Latin American region has undergone many changes - political, economic and social. Early examples of neo-liberalism in the mid 1990s were followed by mixtures of socialist, collective and entrepreneurial models adopted by both governments and organisations. Many countries have embraced the notion of entry into the global arena whilst failing to recognise its diverse impacts. The historical trajectories of these actors are converging, making it possible to attempt explorations of the impact of organisational and managerial practices. In this region, research must take into account both the emergence of indigenous manifestations and localisation of foreign enterprises and businesses, as well as how some countries have expanded their operations in neighbouring areas, to the North or the East (e.g. the United States and Canada, Europe, China). Business traffic moves both from and to Latin America.

Despite this apparently favourable state of affairs, reinforced by the promising and sustained indexes of economic growth in many countries, many pressing issues remain unresolved, including poverty, education and violence. Some governments leave to private enterprises and entrepreneurs the responsibility of dealing with the basic living conditions of the population; others take full control. Businesses also have converted some issues into opportunities. The end result reflects a mixture of partnerships, alliances, agreements, modes and regimes that demonstrate just how complex and multifarious the Latin American context is, the methods organisations have learned to operate in this context and what their experiences, pitfalls, achievements and possibilities teach us. We also need a better understanding of the motivations for and consequences of corporate social responsibility (CSR) in this setting, as well as a recognition of the impacts of internationally oriented CSR practices, beyond the constraints of a company and into the communities and the physical environment.

This special issue aims to provide such a better understanding of how organisations have advanced the idea of CSR, with a view towards the historic conditions that might facilitate its development, if not re-conceptualisation, in a Latin American context. We have pursued research that reflects the rich and diverse mixture of experiences of CSR in the region to identify common elements and trends, as well as learn from their diversity and specificity. This special issue stresses the possibility of using CSR as an opportunity for many organisations that can learn and benefit from what has happened elsewhere, whether regionally or internationally.

\section{Structure and context of the special issue}

The 10 articles selected for this special issue illustrate various ways in which organisations operating in Latin America understand, strategise for and implement CSR, as well as how they are perceived by their stakeholders and influenced by CSR-related expectations. The focal organisations include local companies and foundations, as well as multinational companies (MNCs) from Europe and North America and their subsidiaries. They operate in varied geographical, economical and cultural contexts across Latin America. The articles also cover the spectrum from specific discussions of CSR initiatives and policies to broad assessments based on large, multiindustry data sets. This special issue classifies these important contributions into three parts.

The first part focuses on aspects related to CSR understanding, strategy and implementation, including initiatives fairly common to both local organisations and subsidiaries of MNCs that operate 
in Latin America. Of the four articles in this section, the first two add significantly to our ability to analyse the motives of organisational actors for developing CSR policies and initiatives.

In 'Stakeholder pressures and strategic prioritisation: an empirical analysis of environmental responses in Argentinean firms', Diego A. Vasquez-Brust, Catherine Liston-Heyes, Jose A. Plaza-Ubeda and Jeronimo Burgos-Jimenez regard corporate motivations for engaging in CSR policies and initiatives through a stakeholder theory lens. The authors propose six hypotheses related to the relationship between stakeholder environmental pressures and stakeholder salience. With a cross-sectional survey of 505 CEOs of companies that operate in 'polluting' industries, these authors outline some general variations in the way Argentinean companies perceive and address the expectations of diverse stakeholder groups. In particular, managers' perceptions of stakeholder pressures relate closely to the importance stakeholders have for decision making and strategising. This empirical understanding of corporate environmental responsiveness patterns among Argentinean corporate actors also suggests an agenda for parallel investigations in other contexts that analyse corporate environmental responsiveness and other CSR-related acts.

The second article, 'CSR, sustainability, and the meaning of global reporting for Latin American corporations', by Luis A. Perez-Batres, Van V. Miller and Michael J. Pisani, focuses on why companies in six South American countries vary in their CSR engagement, according to the United Nations Global Compact and the Global Reporting Initiative (GRI). These authors adopt institutional and punctuated equilibrium theories, and cite three key filters: commercial, state-signalling and distinguished peers. Thus, they find that specific normative (i.e. European influence in the home country) and mimetic (i.e. company stock listing) pressures push the adoption of international public CSR standards and guidelines.

In the third article, 'The evolution of corporate social reporting practices in Mexico', Moriah Meyskens and Karen Paul complement Perez-Batrez et al.'s research efforts by assessing general CSR reporting efforts by both local Mexican companies and subsidiaries of MNCs operating in Mexico. In order to assess the use of global reporting standards and guidelines (e.g. GRI) and local reporting norms, this study investigates two groups of corporate actors: early and late adopters of CSR-related reporting practices. The typical CSR reporting path for Mexican corporate actors appears to begin with the use of local norms that focus on a local audience, then moves on to more international standards and concrete reporting practices that reflect the expectations of a wider range of stakeholders. Any corporate, political or societal actors that aim at foster cultural and CSR-related change among Mexican business actors should take this pathway into consideration.

Adam Lindgreen, José-Rodrigo Cordoba Pachon, François Maon and José M. Mendoza address CSRrelated strategy development processes in Latin America in 'Corporate social responsibility in Colombia: making sense of social strategies'. With a multiple case study in a Colombian context, these authors propose a framework for CSR activities along a continuum of practices. Empirical evidence from the history of 10 local organisations' CSR policies and initiatives reveals that these strategies fundamentally reflect companies' inherent aspirations to 'do something' and depend on various aspects of their core business strategies, such as cost and diversification. Thus, different organisations follow different trajectories; in Colombia, the social strategies often differ greatly from more established North American or European CSR preconceptions. The constructive, ethically driven agenda this article provides may help researchers 'do something' too by going beyond conventional views on CSR.

The three articles that constitute the second part of the special issue focus on the complex issues global corporate actors face when designing and implementing their CSR policies in both international and Latin American contexts. In 'How do leading retail MNCs leverage CSR globally? Insights from Brazil', Luciano Barin Cruz and Dirk M. Boehe identify four key CSR-related challenges that MNCs must address to develop CSR policies: global integration and performance, the creation of CSRbased competitive advantages, local capabilities and responsiveness, and worldwide learning processes. The notion of transverse CSR management may provide an effective means to face these challenges constructively; its key mechanisms suggest this approach can be implemented flexibly and comprehensively. This case study-based article generates 
insights for researchers regarding CSR by MNCs, but it also offers practical implications for managers who need to develop CSR programs across their MNCs.

Lars Huemer, in his article, 'Corporate social responsibility and multinational corporation identity: Norwegian strategies in the Chilean aquaculture industry', adopts an organisational identity perspective towards such challenges. The longitudinal comparison of identity issues and CSR policies at two Norwegian MNCs reveals a key role of organisational identity and the importance of translating hyper-norms into organisational principles, which then can become contextualised organisational practices. Through this process, MNCs can design and implement locally pertinent CSR policies and initiatives.

The seventh article, 'Responsible retailing: the practice of CSR in banana plantations in Costa Rica' by Pamela K. Robinson, focuses on the CSR-related challenges to actors at both ends of global agribusiness supply chains. In this setting, CSR policies and commitments to voluntary labour initiatives by retailers in developed countries may not be effective for improving the widely varying working conditions of workers in plantations. However, this article offers some possible and desirable changes to retailers' behaviours that can ensure competitive sustainability, as well as consumer trust in the retailer and its activities.

Finally, the last section and its three articles address specific concerns related to the impact of developing and communicating about CSR policies and activities, for both individuals and organisational performance. In 'Consumer reactions to CSR: a Brazilian perspective', Sergio W. Carvalho, Sankar Sen, Marcio de Oliveira Mota and Renata Carneiro Lima attempt to generalise existing theories to a largely forgotten population. When a CSR-related initiative also induces a price increase, perceptions of the company as socially responsible depend on consumers' purchase intentions, as well as their likelihood to switch to a competitor or complain about the price increase. This study also highlights some mediators, such as perceived price fairness and personal satisfaction, which also appear contingent on the level of Brazilian consumers' purchasing power.

In order to test the six hypotheses in 'Corporate behaviour, social cynicism, and their effect on individuals' perceptions of the company', Claudio
Aqueveque and Catherine Encina investigate the effects of CSR-related features on the antecedents of a company's performance, such as corporate trustworthiness and perceived product quality. In a Chilean context, CSR has a null effect on perceived corporate trustworthiness, but the perceived corporate work environment has a significant influence on perceived product quality. Yet among socially cynical consumers, positive perceptions of the corporate work environment enhance perceptions of corporate trustworthiness only if the company appears to perform its CSR poorly. Overall, the article substantiates that Latin Americans, and more particularly Chileans, adopt particular and unique interpretations and inferences of corporate social behaviours.

Finally, the last article of this special issue considers the relationship between CSR-based product differentiation and export performance. In 'Corporate social responsibility, product differentiation strategy and export performance', Dirk M. Boehe and Luciano Barin Cruz use structural equation modelling and demonstrate that innovation and CSR-based product differentiation predict the export performance improvement of Brazilian companies better than does quality differentiation, though these relationships appear contingent on the market scope of the exporting company. By combining CSR and international business research, these authors reveal that international trade processes can spread CSR activities from export destinations to exporters, which helps explain the link between emerging CSR practices in Latin America and those developing in other parts of the world, especially developed countries.

\section{Acknowledgements}

We take this opportunity to thank, first of all, those who contributed to this special issue of Journal of Business Ethics. The reviewing was a double-blind process; we greatly appreciate the work of the reviewers who committed to providing timely feedback to the authors, thereby helping these authors improve their manuscripts: Debra Basil, Thomas Beschorner, Michael Beverland, Ben Bradshaw, Manuel Emílio Mota de Almeida Castelo Branco, Chauncey Burke, Edith Callaghan, Roberto García Castro, Pepe Lee Chang, David Clough, Luciano Barin Cruz, Paul Custance, John 
Dienhart, Luciana Ferreira, Frank Figge, Ina Freeman, Yongqiang Gao, Frank Jan de Graaf, Timothy Hargrave, David Harness, Sue Hart, Irene Henriques, Colin Higgins, Martin Hingley, David Holdsworth, Richard Hudson, Karianne Karlshoven, Arno Kourula, Gregory Klages, Jennifer Lai, Jairo Lugo, François Maon, Domenec Mele, J. Longinos Marín Rives, Christine Vallaster, Joëlle Vanhamme, Keith Walley and Tina $\mathrm{Xu}$. We also extend special thanks to the editor Alex Michalos for giving us the opportunity to guest edit this special issue of Journal of Business Ethics. Last but not least, we warmly thank all of the authors who submitted their manuscripts for consideration in Journal of Business Ethics. We appreciate and are grateful for the authors' desire to share their knowledge and experience with the journal's readers - and for their willingness to have their views put forward for possible challenge by their peers. We are confident that the articles in this special issue contribute to a greater, more detailed understanding of CSR in Latin America. As well, we hope the selected articles generate the kind of dialogue that is necessary to further understanding in this important area.

Adam Lindgreen Business School, University of Birmingham, Edgbaston, Birmingham B15 2TT, U.K.

E-mail: a.lindgreen@bham.ac.uk and

IESEG School of Management, Lille, France

José-Rodrigo Córdoba School of Management, Royal Holloway, University of London, Egham, Surrey TW20 OEX, U.K. E-mail:J.R.Cordoba-Pachon@rhul.ac.uk 